\title{
INVESTIGATION ON FRACTURE OF EPOXY-FILLED COMPOSITES BY ACOUSTIC EMISSION
}

\author{
Aleksandr K. ARNAUTOV, Oskars BIKOVENS ${ }^{\mathrm{b}}$, Viktor GRIBNIAK ${ }^{\mathrm{c}}$, \\ Aleksejs NASIBULLINS ${ }^{\text {a }}$, Ilmars BLUMBERGS ${ }^{\mathrm{a}}$, Maris HAUKA ${ }^{\mathrm{a}}$ \\ a Institute of Polymer Mechanics (IMP), University of Latvia, Raina blvd. 19, LV-1586 Riga, Latvia \\ ${ }^{b}$ Latvian State Institute of Wood Chemistry, Dzerbenes str. 27, LV-1006 Riga, Latvia \\ ${ }^{c}$ Research Laboratory of Innovative Building Structures, Vilnius Gediminas Technical University, \\ Sauletekio av. 11, LT-10223 Vilnius, Lithuania
}

Received 08 Jan 2016; accepted 17 Feb 2016

\begin{abstract}
Acoustic emission (AE) technique is widely used to monitor failure processes in composite materials including development of cracks and plastic deformations within the polymer matrix, fracture and debonding of inclusions, etc. In this study, the AE technique was applied investigating failure character of epoxy polymers with different content of nanofiller - fine polyethersulfone (PES) powder. Variation of material properties of the epoxy with $0,5 \%, 7.5 \%, 10 \%$, and $12.5 \%$ concentration (by weight) of the PES was assessed experimentally. Correlation between the PES content and the modulus of elasticity was found negligible. The same was characteristic for the tensile strength. Whereas, such a correlation was found significant for the fracture toughness that increased 1.5 times concerning the pure epoxy reference. Analysis of the cumulative AE counts indicated existence of three different stages of the damage accumulation process, which were unidentified using the load and the deformation diagrams. In the PES-modified composites, the damage accumulation process was evidenced at the $10-20 \%$ of the ultimate load; whereas, in the pure epoxy, such a process was fairly slow until the $85 \%$ of the loading.
\end{abstract}

Keywords: epoxy-filled composite, acoustic emission, tensile test, damage accumulation.

\section{Introduction}

Wide industrial application is characteristic for epoxybased polymers. Among many others, recent studies by the authors (Gribniak et al. 2014, 2015; Arnautov et al. $2015,2016)$ can be mentioned in this context.

Common adhesives and fibre-reinforced composites are based on crosslinked thermosetting epoxy polymers. Exhibiting high strength and modulus of elasticity, these polymers are characterized by a low fracture toughness and resistance for impact and fatigue (Thomas et al. 2015). The brittleness is a consequence of high crosslinkdensity constrained plastic deformations of the polymers (Argon, Cohen 2003). Stress concentrators may initiate cracks resulting in a sudden failure. Thus, structural application of the epoxy polymers is still limited.

A number of studies was dedicated to improve the epoxy toughness seeking do not affect the proficient mechanical properties - the high strength and modulus of elasticity (Chandrasekaran et al. 2014). Wetzel et al. (2006) investigated enhancing the toughness of epoxies by addition of elastomeric or thermoplastic modifiers. The phase separation of additional components with- in the polymer matrix improves the fracture toughness by shielding the crack tip (Chruściela, Leśniaka 2015). Though characterized by a high fracture resistance, the rubber-modified epoxies possess a reduction of other important physical properties, including the glass transition temperature (Guan et al. 2015; Wang et al. 2015). Increased fracture toughness is a specific property of the lightly crosslinked epoxies (Chandrasekaran et al. 2014; Leonardi et al. 2015).

An alternative toughness improving technology is based on application of thermoplastic particles that disclosed an outstanding advantage over the elastomericmodified systems (Deng et al. 2015). Despite a noticeable progress in synthesizing the thermoplastic particles, fracture mechanism of the modified epoxies, governed by interaction between the polymer and fillers (so-called bridging effect), remains vague.

Acoustic emission (AE) is one of the most promising techniques for investigating fracture of the composite materials (Wevers 1997; Klepka et al. 2014; Chaki et al. 2015). Guerjouma et al. (2001) revealed that AE, repre-

Corresponding author: Viktor Gribniak

E-mail: viktor.gribniak@vgtu.lt 
senting the generation of transient ultrasonic waves in a material under load, is a powerful tool for in-situ damage and failure analysis of composites. It is effective for assessing development of cracks and plastic deformations within the polymer matrix, fracture of the inclusions, debonding of the components, etc.

This paper involves $\mathrm{AE}$ technique for identification of the failure mechanism characteristic for epoxy composite modified using polyethersulfone powder as nanofiller. The main idea of the research is to relate the toughness (i.e. release of the deformation energy) with the failure character that, in the considered case, can be associated with debonding of the nanoparticles or development of cracks within the polymer matrix. Both these options are identified by means of the AE.

\section{Materials and test setup}

\subsection{Materials}

In this study, material properties of a standard epoxy polymer bisphenol-A diglycidyl ether resin Araldite $L Y$ 1564 cured by aliphatic polyamine hardener Aradur 3486 were investigated (both components were provided by the Huntsman Corp., Switzerland). Fine polyethersulfone powder Ultrason ${ }^{\circledR}$ E 2020 P SR micro (PES) provided by the BASF (Germany) with minimum $50 \%$ content of $\mathrm{OH}$-endgroups (having a typical particle size below $100 \mu \mathrm{m}$ ) was used as the nanofiller. Molecular weight of the PES was $55000 \mathrm{~g} / \mathrm{mol}$. The PES filler content in the epoxy resin was varied in the range $5-12.5 \%$ (by weight).

To avoid conglomeration of micro particles with dimensions of several micrometers due to interactive forces between the nanoparticles, the epoxy composite was mixed with $10000 \mathrm{rpm}$ rate during one hour using high shear mixer Silversone L5M-A (East Longmeadow, MA) with a square hole head mixing screen. The hardener (34\% by weight of the epoxy resin) was added to the homogenized mixture further stored in the vacuum for 15 minutes to avoid formation of structural defects (air bubbles). The homogenized mixture was poured into the aluminium moulds and cured at $100{ }^{\circ} \mathrm{C}$ for 4 hours.

\subsection{Mechanical loading and AE}

Mechanical properties of the epoxy resin were determined in static tensile tests, which were conducted at ambient temperature using Zwick/Roell 2.5 testing machine and MISTRAS-Micro II Digital AE system with R6-Alpha sensor. Figure 1 shows the test setup. The operating frequency range of the sensor was $0-900 \mathrm{kHz}$. High vacuum silicone grease was used as a couplant. The amplitude distribution covers the range of $0-80 \mathrm{~dB}(1 \mathrm{~dB}$ corresponds to $1 \mu \mathrm{V}$ at the transducer output). An ambient noise below the limit of $30 \mathrm{~dB}$ was filtered. Dominant AE parameters such as amplitude, counts, rise time, energy and duration were recorded.

Six dog-bone specimens (Fig. 2) for each of the considered concentrations of PES $(0,5 \%, 7.5 \%, 10 \%$, and $12.5 \%$ ) were tested in accordance with the ASTM 638

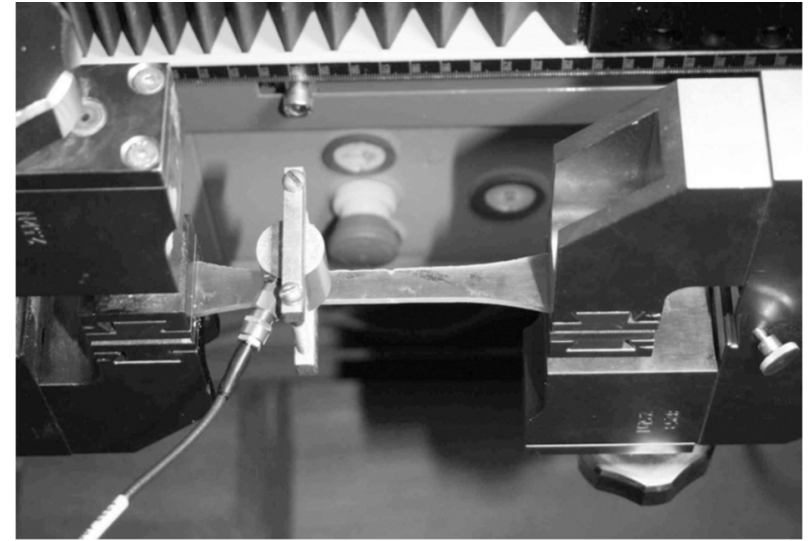

Fig. 1. Test setup

standard. The sample size was $2 \times 10 \times 150 \mathrm{~mm}$. The loading was controlled by crosshead displacement at constant velocity of $2 \mathrm{~mm} / \mathrm{min}$. From the test results, the Young modulus, the yield stress and the respective strain were determined.

The static fracture toughness was determined by means of the compact tension test in accordance with the ASTM D5045-14 (2014) and ASTM E399 (2012) standards using the chevron notch specimen shown in Figure 3. At least four samples were tested at deformation speed of $10 \mathrm{~mm} / \mathrm{min}$. The notch was machined and

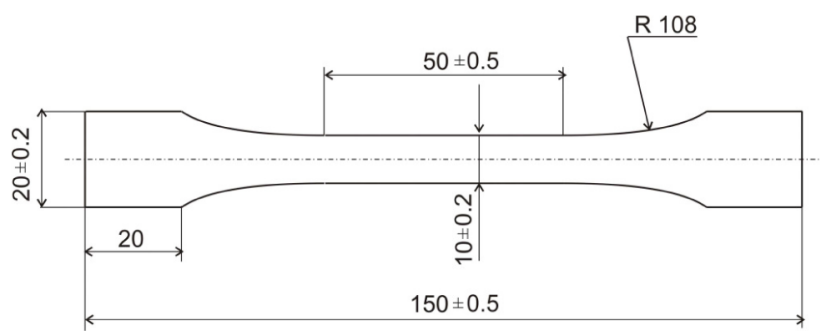

Fig. 2. The test sample (dimensions in $\mathrm{mm}$ )

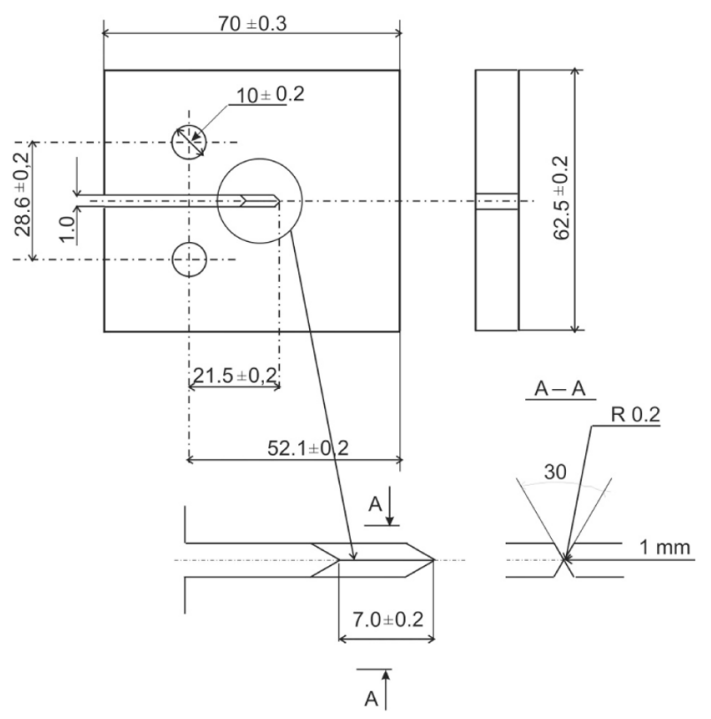

Fig. 3. The compact tension test sample (dimensions in $\mathrm{mm}$ ) 
sharpened using a razor blade. The length of sharp crack $a_{0}$ was varied between $0.45 \mathrm{~W}$ and $0.55 \mathrm{~W}$, where $W$ is the specimen width. The crack length $a_{0}$ was determined on fractured surfaces by using an electronic calliper with a scale interval $0.01 \mathrm{~mm}$. The fracture toughness $K_{1 c}$ was calculated as:

$$
K_{1 c}=f(x) \frac{P}{B \sqrt{W}},
$$

where $P$ is the maximum force from the load-displacement curve; $a_{0}$ is the initial crack length; the function $f(x)$ is approximated as:

$$
\begin{gathered}
f(x)=k_{\alpha} \frac{2+\alpha}{(1-\alpha)^{3 / 2}} ; \quad \alpha=\frac{a_{0}}{W}, \\
k_{\alpha}=0.866+4.46 \alpha-13.32 \alpha^{2}+14.72 \alpha^{3}-5.60 \alpha^{4} .
\end{gathered}
$$

The glass transition temperatures $(\mathrm{Tg})$, the region where polymer transits from a hard to a rubbery state, were determined by means of differential scanning calorimetry using Star DSC 823e equipment (Mettler Toledo, Switzerland). The twin-samples of $8 \mathrm{mg}$ weight were vacuum oven-dried with $10^{\circ} \mathrm{C} / \mathrm{min}$ heating rate between $20{ }^{\circ} \mathrm{C}$ and $300{ }^{\circ} \mathrm{C}$. In accordance with recommendation by the DIN 53765 (1994) standard, the double scanning (repeated heating) procedure was applied for elimination of the violate components of the epoxy increasing reliability of the assessments. The temperature $\mathrm{Tg}$ of the pure epoxy Araldite LY 1564 cured by aliphatic polyamine hardener Aradur 3486 was equal to $100{ }^{\circ} \mathrm{C}$, whereas the PES modification increased Tg up to $228{ }^{\circ} \mathrm{C}$. Such increase indicates appearance of the second phase with relatively higher $\mathrm{Tg}$ than the pure epoxy reference.

\section{Experimental results and discussion}

Table 1 shows variation of the tensile strength, the elastic modulus, and the strain at the maximum load and the respective energy release with the PES content. The characteristic experimental stress-strain curves of the pure epoxy resin and the epoxy with various concentrations of the PES $(5 \%, 7.5 \%, 10 \%$, and $12.5 \%)$ specimens are shown in Figure 4. Although having no sense on variation of the strength and the modulus of elasticity, increase in the PES content significantly correlates with the fracture toughness $\left(\mathrm{K}_{\mathrm{Ic}}\right)$. The reduction of the mechanical parameters of the epoxy with $12.5 \%$ of the PES (Table 1) can be associated with an increase of internal defects in the polymer matrix with the maximum content of nanofiller.

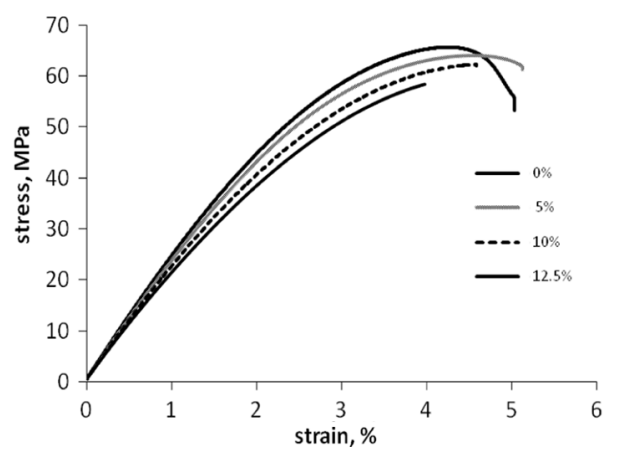

Fig. 4. Typical stress-strain curves of the epoxy specimens with different content of the PES filler

Analysis of the material properties (Table 1) reveals existence of a small negative correlation between the PES content and the tensile strength as well as the modulus of elasticity of the epoxies with the $5-10 \%$ PES content. The fracture toughness significantly correlates with the PES content reaching $1.01 \mathrm{MPa} / \mathrm{m}^{0.5}$ for the epoxy with $10 \%$ of the PES. With an increase of the PES up to $12.5 \%$, the strength, the modulus of elasticity, and the fracture toughness decrease noticeably. Furthermore, failure of the epoxy with the maximum content of the PES was not associated with the yielding process characteristic for all other epoxies.

The analysis was carried out in two steps. First, the $\mathrm{AE}$ was applied to identify frequencies associated with the damage accumulation process and failure of the epoxy composites. Second, the effect of the PES powder content on the mechanical properties of the epoxy was assessed analysing the AE spectra and frequencies with maximum amplitude determined for the selected samples.

For comparison purposes, Figure 5 shows the normalized diagrams (the applied load, the strain, and the cumulative AE counts averaged using 5-6 samples) determined for the pure epoxy and epoxy composites with different concentration of the PES. Variation of the AE signals reveals existence of three altered stages of the loading behaviour indicated in Figure 5.

An initial stage of stable variation of cumulative AE counts (Stage I in Fig. 5) is characteristic for the pure epoxy at the loading below $6 \%$ of the ultimate value; for the PES-filled epoxies, this stage is limited by $10-20 \%$ of the ultimate loads. At this stage, variation of the mechanical parameters of the samples is almost linear, i.e. not any damages were accumulated in the materials.

Table 1. Effect of the PES content on mechanical properties of the epoxy resin

\begin{tabular}{c|c|c|c|c|c|c}
\hline $\begin{array}{c}\text { PES } \\
\text { content, \% }\end{array}$ & $\begin{array}{c}\text { Tensile } \\
\text { strength, MPa }\end{array}$ & $\begin{array}{c}\text { Modulus of } \\
\text { elasticity, GPa }\end{array}$ & $\begin{array}{c}\text { Strain at } \\
\text { max load, \% }\end{array}$ & $\begin{array}{c}\text { Strain at } \\
\text { failure, \% }\end{array}$ & $\begin{array}{c}\text { Energy release } \\
\text { at max load, J }\end{array}$ & $\begin{array}{c}\text { Fracture } \\
\text { toughness, MPa/m } \mathrm{m}^{0.5}\end{array}$ \\
\hline 0 & $64.0 \pm 1.0$ & $2.36 \pm 0.03$ & $4.4 \pm 0.03$ & $5.0 \pm 0.3$ & $4.5 \pm 0.4$ & $0.64 \pm 0.07$ \\
5.0 & $61.5 \pm 1.5$ & $2.47 \pm 0.07$ & $4.0 \pm 0.01$ & $4.3 \pm 0.2$ & $4.2 \pm 0.2$ & $0.72 \pm 0.09$ \\
7.5 & $61.4 \pm 1.0$ & $2.36 \pm 0.03$ & $4.4 \pm 0.03$ & $4.8 \pm 0.4$ & $4.8 \pm 0.1$ & $0.85 \pm 0.11$ \\
10.0 & $61.8 \pm 0.8$ & $2.37 \pm 0.05$ & $4.5 \pm 0.01$ & $4.7 \pm 0.1$ & $4.8 \pm 0.3$ & $1.01 \pm 0.13$ \\
12.5 & $57.6 \pm 0.8$ & $2.21 \pm 0.03$ & $3.9 \pm 0.03$ & $3.9 \pm 0.3$ & $3.7 \pm 0.2$ & $0.84 \pm 0.16$ \\
\hline
\end{tabular}


(a)

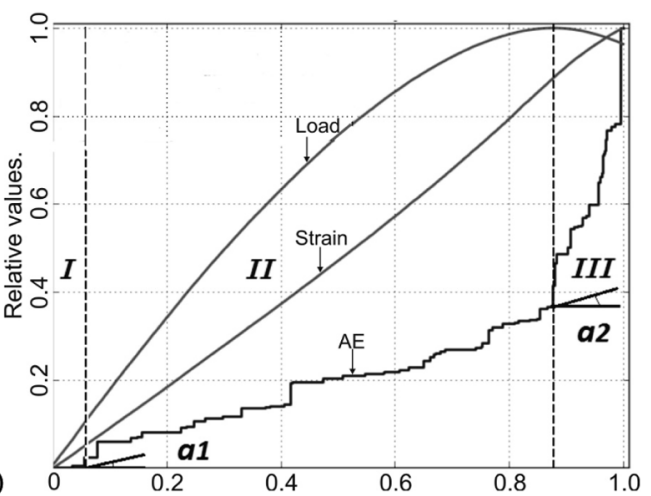

(c)

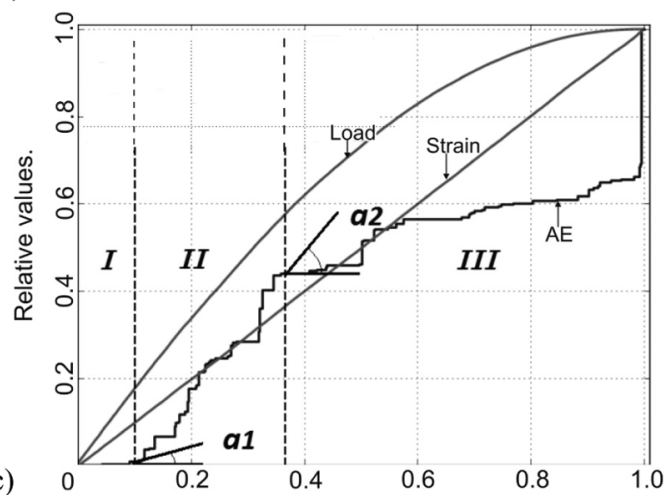

(b)

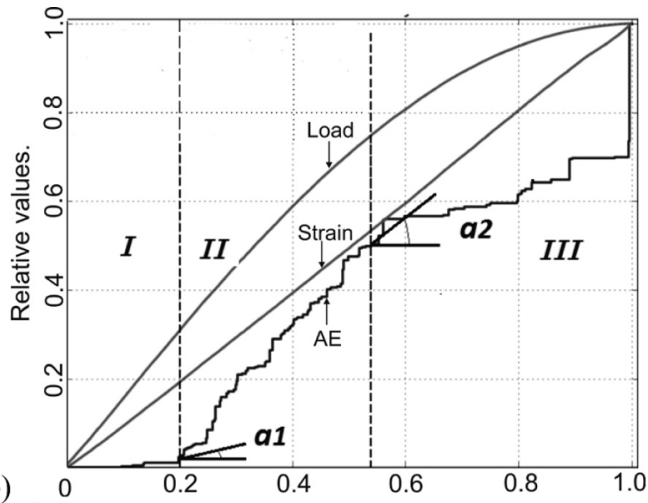

(d)

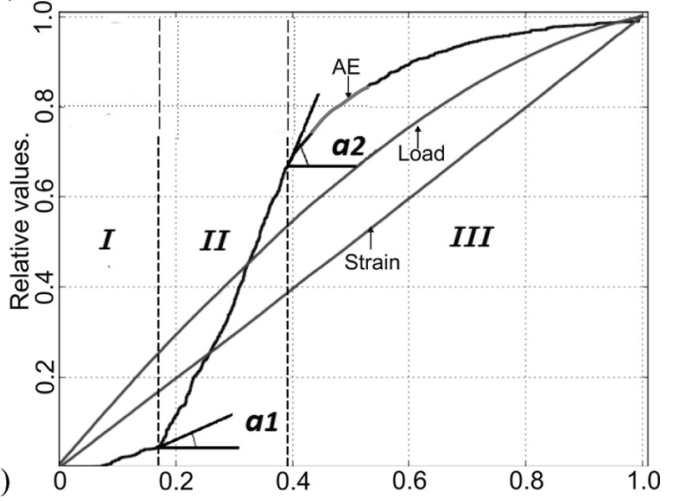

Fig. 5. Normalized diagrams: (a) reference pure epoxy; (b) epoxy resin with 5.0\%, (c) - 10.0\%, and (d) - $12.5 \%$ of the PES filler

The second stage is characteristic for the pure epoxy resin at the loading range from $6 \%$ to $85 \%$ of the ultimate load, whereas, for the modified epoxies, this stage is related with the $10-50 \%$ loading interval. At this stage, a gradual increase of the cumulative counts (Fig. 5a) indicates initial accumulation of the damages in the pure epoxy. Whereas, the noticeable increase of the AE counts (Figs 5b-5d) reveals a rather intensive accumulation of the defects in the PES-filled composites.

Figure $5 \mathrm{~b}$ reveals noticeable increase of the AE counts within the range of $20-55 \%$ of the ultimate load for the epoxy with 5\% of the nanofiller, though not any evident changes are observed in the load and the deformation diagrams. Similar results can be observed for the epoxy with $10 \%$ of the PES (Fig. 5c) with exception of the boundary values of the second stage that is associated with the 10-37\% loading range. (Possessing exactly the same output as the $5 \%$ and $10 \%$ counterparts, results obtained for the epoxy with $7.5 \%$ content of the PES are not presented in Fig. 5).

For the pure epoxy, the final third loading stage is related to the yielding process that is evidenced by a significant increase of the cumulative AE counts (Fig. 5a). For the PES-modified epoxies, the third stage is associated with reduction of the AE activity; a non-linear response can be observed in the loading curves. The yielding of the specimen with $5 \%$ of the PES (the loading range $55-100 \%$, Fig. 5b) initiates drastic increase of the cumulative AE counts that leads to failure of the sample. Analogous results are typical for the epoxy with $10 \%$ of the PES (Fig. 5c): a decrease of the AE activity from almost $40 \%$ of the ultimate load is followed by formation of cervical due to yielding of the epoxy. Failure of the sample is characterized by non-linear deformations and drastic increase of the AE counts. The different behaviour is specific for the polymer with $12.5 \%$ of the PES (Fig. 5d) that fall due to gradual accumulation of the defects rather than in consequence of the yielding of epoxy.

The obtained results indicate capability of the AE technique identifying frequencies characteristic for the damage accumulation and failure of the epoxy resins. Evolution of the cumulative AE activity (Fig. 5) reflects an accumulative nature of failure of the epoxies:

1. Low cumulative counts are associated with an absence of significant damages at the first loading stage.

2. The second loading stage is associated with an intensive accumulation of defects within the structure of the PES-modified polymers. Whereas, in the pure epoxy, this process has a gradual less intensive character.

3. A decrease in the AE activity with further drastic increase of the cumulative counts is characteristic for the epoxies with $0-10 \%$ content of the PES at the third loading stage. It can be related to formation of a cervical due to the yielding of epoxy. In the pure epoxy, this process was very intensive. Failure of the epoxy with the maximum content of the PES was a result of gradual accumulation of the defects. 

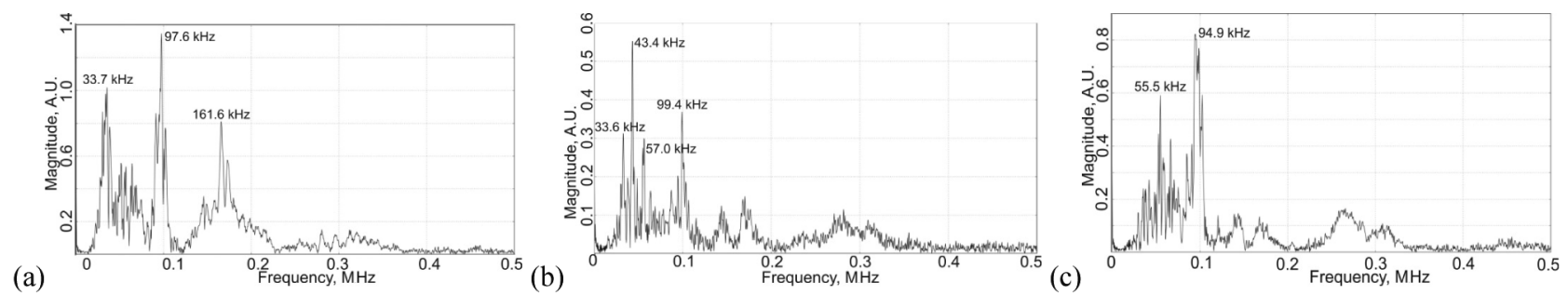

Fig. 6. AE amplitude spectra for the pure epoxy: (a) first loading stage - below $6 \%$ of the maximum load; (b) second stage $6 \%-88 \%$ of the maximum load; (c) third stage - above $88 \%$ of the maximum load

(a)

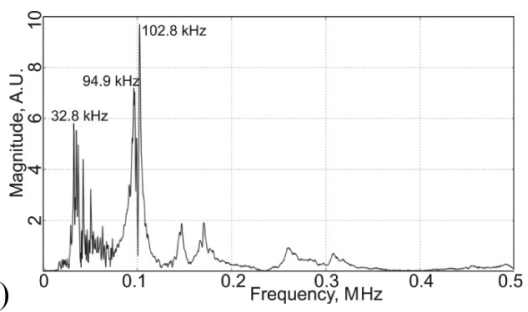

(b)

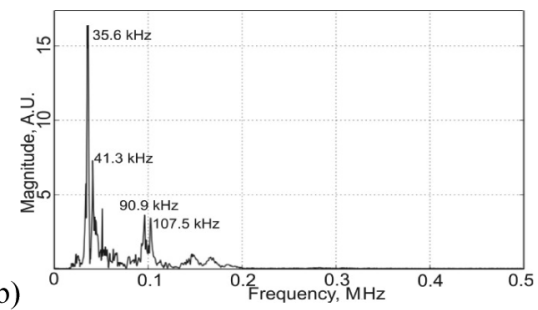

(c)

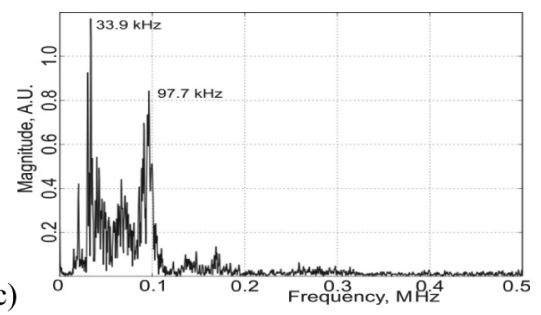

Fig. 7. AE amplitude spectra for the epoxy resin with $12.5 \%$ of the PES: (a) first loading stage - below $20 \%$ of the maximum load; (b) second stage $-20-40 \%$ of the maximum load; (c) third stage - above $40 \%$ of the maximum load

Further comparative analysis of the failure mechanism is performed considering the epoxies with 0 and $12.5 \%$ contents of the PES. For these representative compositions, the AE spectra and frequencies with maximum amplitude were determined at the loading stages indicated in Figure 5. The resultant spectra of the AE signals emitted by both compositions are shown in Figures 6 and 7. The first loading stage can be associated with a relatively low AE activity detected for both epoxies: $30-50 \mathrm{kHz}$ frequencies along to $100 \mathrm{kHz}$ dominant are evidenced from Figures $6 \mathrm{a}$ and $7 \mathrm{a}$. Noticeably higher amplitude is characteristic for the PES-modified epoxy that reveals absence of the defects in the pure epoxy and initiation of the damage accumulation process in the PESfilled counterpart.

At the second loading stage, the two dominant ranges $(30-50 \mathrm{kHz}$ and $100 \mathrm{kHz})$ are characteristic for both epoxies. In the filled epoxy (Fig. 7b), intensity of the low frequencies (with the peak value of $35.6 \mathrm{kHz}$ ) was increased though reducing width of this diapason; the frequencies in the $100 \mathrm{kHz}$ range were also increased, but less intensive than in the $30-50 \mathrm{kHz}$ region. In the pure epoxy, reduction of the frequency amplitude was accomplished by the increase of the cumulative AE counts (Figs $5 \mathrm{a}$ and $6 \mathrm{~b}$ ). This process can be associated with the formation of the cervical due to yielding of the epoxy and consequent increase of the density and closure of the cracks. The modified epoxy did not approach the yielding process though accumulated a significant portion of damages at the second loading stage (Fig. 5d).

The increase of AE activity in the pure epoxy at the third loading stage (Fig. 5a) can be attributed to the drastic accumulation of the defects in the yielding zone that also contributed to the increase of the frequency am- plitude (Fig. 6c). The increase of the cumulative counts (Fig. 5d) was reduced concerning the previous loading stage. The dominant frequencies remained the same (as at the previous stage) for both epoxies (Figs $6 \mathrm{c}$ and $7 \mathrm{c}$ ).

The increase in the frequency amplitude observed for the pure epoxy (Fig. 6) can be associated with opening of magisterial cracks, which lead to a failure of the specimen. The frequency amplitude in the PES-modified epoxy (Fig. 7c) decreases significantly concerning the previous loading stage (Fig. 7b), though remains higher than observed for the reference epoxy. The same result is characteristic for the cumulative counts (Fig. 5). These indicate significant quantity of the defects accumulated within the PES-modified matrix that contributes to the earlier failure of the specimen concerning the reference counterpart (Fig. 4).

Bak et al. (2016) associated the AE frequency range of $100 \mathrm{kHz}$ with the failure of epoxy. Analysis of the resultant spectra of the AE signals emitted by the epoxy with boundary contents of the PES (i.e. 0 and $12.5 \%$ by weight) highlights domination of the frequencies within two ranges (30-50 kHz and $100 \mathrm{kHz}$ ), though with a noticeably higher amplitude characteristic for the PESmodified polymer. The analysis did not reveal frequencies characteristic for failure of the PES nanofiller and for separation (debonding) of the matrix components.

\section{Conclusions}

Structural application of epoxy polymers is limited by a low fracture toughness of the thermosetting epoxies. This problem can be solved by using thermoplastic particles, which block development of the micro-cracks within the polymer matrix. However, the nanoparticles interaction mechanism remains vague. 
In this study, acoustic emission (AE) technique was found efficient for identifying the failure mechanism characteristic for the epoxy resin modified using polyethersulfone (PES) powder as the nanofiller. The AE activity was related with deformation behaviour (damage accumulation process) of the epoxy polymers with different concentration of the PES nanofiller. Variation of the material properties (tensile strength, modulus of elasticity, and fracture toughness) of the epoxy with 0 , $5 \%, 7.5 \%, 10 \%$, and $12.5 \%$ concentration of the PES (by weight) were assessed experimentally. The analysis of the results allows making the following conclusions:

1. No significant effect of the PES content on variation of the tensile strength and the modulus of elasticity was observed. Whereas, correlation between the PES concentration and the fracture toughness was found significant: the toughness of the composite with $10 \%$ content of the PES was increased 1.5 times concerning the pure epoxy reference. Further increase in the PES concentration reduces all considered mechanical parameters.

2. A tendency of the increase of the cumulative AE counts under loading indicates the existence of three different stages of the damage accumulation process, which identification using the load and the deformation diagrams is impossible.

3. In the PES-modified composites, a quite intensive damage accumulation process was initiated within the $10-20 \%$ range of the ultimate load, whereas, for the pure epoxy, the intensity of this process was quite low until the $85 \%$ of the loading.

4. Relatively small amplitudes of the AE frequencies are characteristic for the pure epoxy at all loading stages that can be associated with a low activity of the micro-cracking process. Dominant frequencies in the $100 \mathrm{kHz}$ diapason, specific for a failure of the epoxy matrix, are characteristic for the PES-modified epoxies at the third loading stage. This characterises development of the cracks (in the consequence of the damage accumulation). At the first two loading stages, the particles of the PES nanofiller were efficient shielding the crack tips.

\section{Acknowledgements}

The authors gratefully acknowledge the financial support provided by the European Social Fund (Research Project Nr. 2013/0019/1DP/1.1.1.2.0/13/APIA/VIAA/062).

\section{References}

Argon, A. S.; Cohen, R. E. 2003. Toughenability of polymers, Polymer 44(19): 6013-6032. http://dx.doi.org/10.1016/S0032-3861(03)00546-9

Arnautov, A. K.; Nasibullins, A.; Gribniak, V.; Blumbergs, I.; Hauka, M. 2015. Experimental characterization of the properties of double-lap needled and hybrid joints of carbon/epoxy composites, Materials 8: 7578-7586. http://dx.doi.org/10.3390/ma8115410
Arnautov, A. K.; Kulakov, V.; Andersons, J.; Gribniak, V.; Juozapaitis, A. 2016. Experimental investigation on stiffness and strength of single-lap joints in a laminated CFRP stress-ribbon strip, The Baltic Journal of Road and Bridge Engineering (in press).

ASTM D5045-14. Standard test methods for plane-strain fracture toughness and strain energy release rate of plastic materials. ASTM International, 2014. $10 \mathrm{p}$.

ASTM E399-12e3. Standard test method for linear-elastic plane-strain fracture toughness KIc of metallic materials. ASTM International, 2012. $33 \mathrm{p}$.

Bak, K. M.; Kalaichelvan, K.; Jothilingam, A.; Boopathy, S. R. 2016. Acoustic emission characterization of failure modes of single-lap joints in glass/epoxy specimens, Journal of Composite Materials 50(1): 3-23.

http://dx.doi.org/10.1177/0021998315569749

Chaki, S.; Harizi, W.; Bourse, G.; Ourak, M. 2015. Multi-technique approach for non destructive diagnostic of structural composite materials using bulk ultrasonic waves, guided waves, acoustic emission and infrared thermography, Composites Part A: Applied Science and Manufacturing 78: $358-361$.

http://dx.doi.org/10.1016/j.compositesa.2015.08.033

Chandrasekaran, S.; Sato, N.; Tölle, F.; Mülhaupt, R.; Fiedler, B. 2014. Fracture toughness and failure mechanism of graphene based epoxy composites, Composites Science and Technology 97: 90-99. http://dx.doi.org/10.1016/j.compscitech.2014.03.014

Chruściela, J. J.; Leśniaka, E.; 2015. Modification of epoxy resins with functional silanes, polysiloxanes, silsesquioxanes, silica and silicates, Progress in Polymer Science 41: 67121. http://dx.doi.org/10.1016/j.progpolymsci.2014.08.001

Deng, S.; Djukic, L.; Paton, R.; Ye, L. 2015. Thermoplasticepoxy interactions and their potential applications in joining composite structures - a review, Composites Part A: Applied Science and Manufacturing 68: 121-132. http://dx.doi.org/10.1016/j.compositesa.2014.09.027

DIN 53765 Testing of plastics and elastomeres; thermal analysis; DSC-method. Deutsches Institut Fur Normung E. V. (German National Standard), 1994. 12 p.

Gribniak, V.; Arnautov, A. K.; Kaklauskas, G.; Jakstaite, R.; Tamulenas, V.; Gudonis, E. 2014. Deformation analysis of RC ties externally strengthened with FRP sheets, Mechanics of Composite Materials 50(5): 669-676. http://dx.doi.org/10.1007/s11029-014-9454-7

Gribniak, V.; Arnautov, A. K.; Kaklauskas, G.; Tamulenas, V.; Timinskas, E.; Sokolov, A. 2015. Investigation on application of basalt materials as reinforcement for flexural elements of concrete bridges, The Baltic Journal of Road and Bridge Engineering 10(3): 201-206. http://dx.doi.org/10.3846/bjrbe.2015.25

Guan, L.-Z.; Gong, L.-X.; Tang, L.-C.; Wu, L.-B.; Jiang, J.X.; Lai, G.-Q. 2015. Mechanical properties and fracture behaviors of epoxy composites with phase-separation formed liquid rubber and preformed powdered rubber nanoparticles: A comparative study, Polymer Composites 36(5): 785-799. http://dx.doi.org/10.1002/pc.22995

Guerjouma, R. E.; Baboux, J.-C.; Ducret, D.; Godin, N.; Guy, P.; Huguet, S.; Jayet, Y.; Monnier, T. 2001. Nondestructive evaluation of damage and failure of fiber reinforced polymer composites using ultrasonic waves and acoustic emission, Advanced Engineering Materials 3(8): 601-608. http://dx.doi.org/10.1002/15272648(200108)3:8<601::AID-ADEM601>3.0.CO;2-9

Klepka, A.; Pieczonka, L.; Staszewski, W. J.; Aymerich, F. 2014. Impact damage detection in laminated composites by non-linear vibro-acoustic wave modulations, Composites Part B: Engineering 65: 99-108. http://dx.doi.org/10.1016/j.compositesb.2013.11.003 
Leonardi, A. B.; Zucchi, I. A.; Williams, R. J. J. 2015. Generation of large and locally aligned wormlike micelles in block copolymer/epoxy blends, European Polymer Journal 65: 202-208. http://dx.doi.org/10.1016/j.eurpolymj.2014.11.001

Thomas, S.; Grohens, Y.; Jyotishkumar, P. 2015. Characterization of polymer blends: Miscibility, morphology and interfaces, Vol. 1. Weinheim: Wiley-VCH Verlag GmbH \& Co. KGaA. 994 p.

Wetzel, B.; Rosso, P.; Haupert, F.; Friedrich, K. 2006. Epoxy nanocomposites - fracture and toughening mechanisms, Engineering Fracture Mechanics 73(16): 2375-2398. http://dx.doi.org/10.1016/j.engfracmech.2006.05.018
Wang, Y.; Lakho, D. A.; Yao, D. 2015. Effect of additives on the rheological properties of fast curing epoxy resins, Éptöanyag - Journal of Silicate Based and Composite Materials 67(4): 132-134.

Wevers, M. 1997. Listening to the sound of materials: Acoustic emission for the analysis of material behaviour, $N D T \& E$ International 30(2): 99-106. http://dx.doi.org/10.1016/S0963-8695(96)00051-5

Aleksandr K. ARNAUTOV. Senior Researcher at the Institute of Polymer Mechanics (IMP) of the University of Latvia, Riga, Latvia. $\mathrm{PhD}$ degree obtained from IMP. His research interests include theoretical and experimental studies of deformation and fracture of materials, mechanics of composite structure, and test methods for determining mechanical properties composite.

Oskars BIKOVENS. Researcher at the Latvian State Institute of Wood Chemistry, Riga, Latvia. Dr Chem degree obtained from the University of Latvia. His research interests include analytical chemistry of wood and polymers, synthesis and analysis of physicochemical properties of polymers.

Viktor GRIBNIAK. Senior Researcher, Head of Research Laboratory of Innovative Building Structures at VGTU, Lithuania. PhD degree obtained from VGTU. He is a member of the fib Task Group 2.1 "Serviceability Models". In 2013, he received the ASCE Moisseiff Award for a paper contributing to structural design. His research interests include serviceability analysis and numerical modelling of reinforced concrete (RC) structures, innovative types of reinforcement for concrete.

Aleksejs NASIBULLINS. Researcher at the Institute of Polymer Mechanics (IMP) of the University of Latvia, Riga, Latvia. PhD degree obtained from Riga Technical University (RTU). Research interests include experimental studies of materials and mechanics of composite structure, and test methods for determining mechanical properties composite.

Ilmars BLUMBERGS. Researcher at the Institute of Polymer Mechanics (IMP) of the University of Latvia, Riga, Latvia. PhD degree obtained in RTU. Research interests include practical and experimental studies of composite materials and mechanics of composite structure. Alternative research interests are in field of renewable energy and in particular in use of Stirling type engines for effective energy transformation.

Maris HAUKA. Researcher at the Institute of Polymer Mechanics (IMP) of the University of Latvia, Riga, Latvia. PhD degree obtained from RTU. He is Assistant professor in the Institute of Aeronautics at RTU. Research interests include theoretical and experimental studies and numerical simulations of deformation and fracture of materials and mechanics of composite and metal structure. 